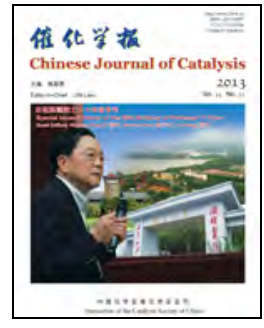

Review (Dedicated to Professor Yi Chen on the occasion of his 80th birthday)

\title{
A mini review on carbon-based metal-free electrocatalysts for oxygen reduction reaction
}

\author{
Lijun Yang †, Yu Zhao †, Shen Chen, Qiang Wu, Xizhang Wang, Zheng Hu* \\ Key Laboratory of Mesoscopic Chemistry of MOE, School of Chemistry and Chemical Engineering, Nanjing University, Nanjing 210093, Jiangsu, China
}

\section{A R T I C L E I N F O}

Article history:

Received 18 August 2013

Accepted 11 September 2013

Published 20 November 2013

Keywords:

Oxygen reduction reaction

Metal-free electrocatalyst

Carbon-based nanostructure

Doping

\begin{abstract}
A B S T R A C T
Exploration of low-cost and high-performance oxygen reduction reaction (ORR) electrocatalysts to replace Pt-based catalysts is now undergoing fast and dynamic development. Metal-free carbon-based ORR electrocatalysts have interesting catalytic activities, high stabilities, and good CO and methanol tolerances, and their constituents are abundantly available. They are therefore potential alternatives to Pt-based catalysts. This paper briefly reviews the main progress in this emerging field, in combination with studies performed by our group. Special attention is paid to electron-rich $\mathrm{N}$ or electron-deficient $\mathrm{B}$ mono-/co-doped carbon nanostructures, and the correlation between the ORR activity and the electronic structure of the $s p^{2}$ carbon material. The bright perspectives are speculated for this new kind of promising metal-free ORR electrocatalysts.
\end{abstract}

(C) 2013, Dalian Institute of Chemical Physics, Chinese Academy of Sciences. Published by Elsevier B.V. All rights reserved.

\section{Introduction}

Fuel cells are clean and efficient energy conversion devices that can directly convert the chemical energy of fuels to electricity through electrochemical processes. Fuel cells using hydrogen or methanol as fuels can be operated at close to room temperature and are considered promising power solutions for future electric vehicles and portable electronic devices. In fuel cells, the fuel is oxidized at the anode, and the released electrons are transferred by the driving circuit to the cathode, where $\mathrm{O}_{2}$ is reduced [1]. The cathodic reaction is the oxygen reduction reaction (ORR), which has sluggish reaction kinetics and usually requires high loadings of Pt-based materials as electrocatalysts. Pt has the problems of scarcity, easy deactivation by CO poisoning, and the fuel crossover effect caused by undesired catalytic oxidation of leaked fuel at the cathode. The performance and costs of fuel cells therefore largely depend on the ORR electrocatalysts used [2]. For decades, much effort has been devoted to developing cheaper and better ORR electrocatalysts, mainly with respect to three aspects, shown in Fig. 1: (1) increasing Pt use efficiency by alloying $[3,4]$ or constructing core-shell structures [5] with other cheap metals, or faceting the active Pt surfaces [6,7]; (2) developing non-precious-metal-based electrocatalysts, such as Fe, Co, Mo, and W [8-11]; and (3) developing metal-free ORR electrocatalysts [12-15]. The emerging metal-free carbon-based ORR electrocatalysts have become a fast-growing branch of ORR electrocatalysts in recent years $[14,15]$.

As is well known, $s p^{2}$ carbon materials have abundant free-flowing $\pi$ electrons, with the potential to act as catalysts for reactions needing electrons, such as the ORR. However, these $\pi$ electrons are too inert to be directly used in the ORR, and they need to be activated before they can be used. The most straightforward method is to put more electrons into the carbon $\pi$ system; this has been achieved by doping $s p^{2}$ carbon materials with electron-rich $\mathrm{N}$ [13]. The extra electrons con-

\footnotetext{
† These authors contributed equally to this work

*Corresponding author. Tel: +86-25-83686015; Fax: +86-25-83686015; E-mail: zhenghu@nju.edu.cn

This work was supported by the National Natural Science Foundation of China $(51232003,21203092,21173114)$.
}

DOI: 10.1016/S1872-2067(12)60713-X | http://www.sciencedirect.com/science/journal/18722067 | Chin. J. Catal., Vol. 34, No. 11, November 2013 


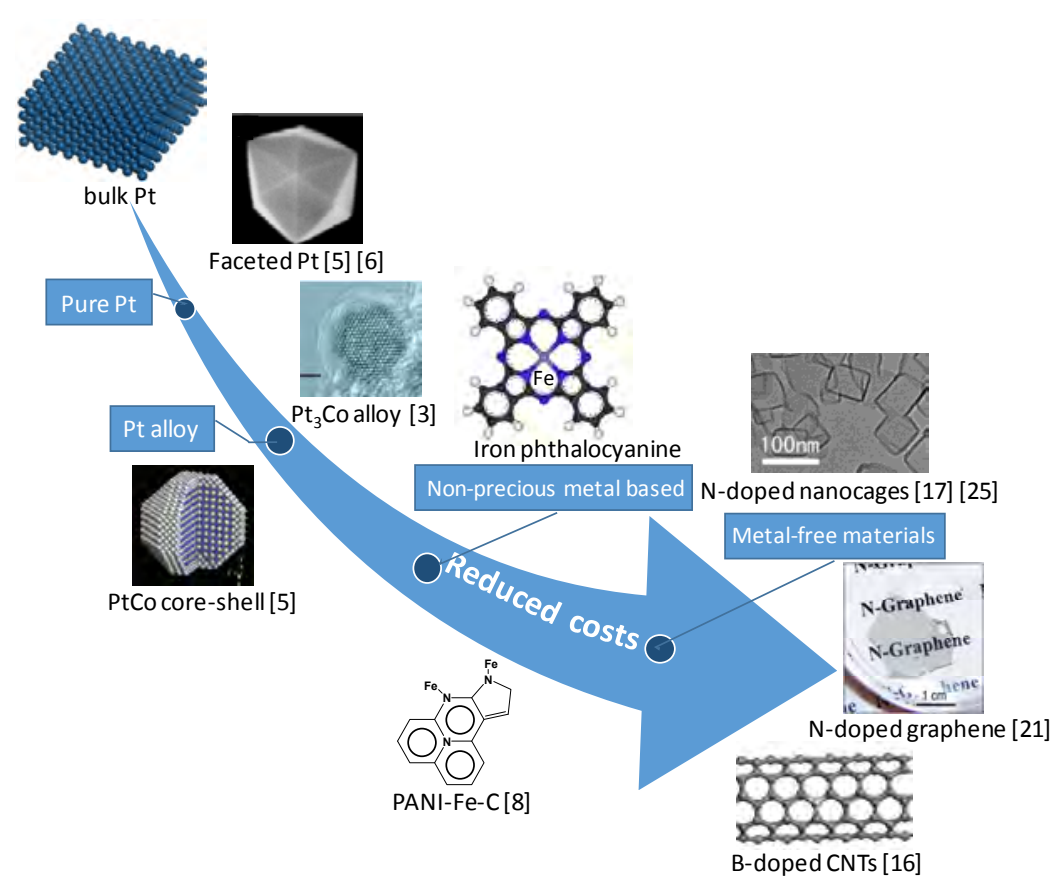

Fig. 1. Expanding family of low-cost ORR electrocatalysts.

tributed by $\mathrm{N}$ increase the electron density and raise the highest occupied molecular orbital (HOMO) energy level of the $s p^{2}$ carbons, facilitating the ORR. Interestingly, the delocalized $\pi$ electrons can also be perturbed by conjugation with vacant orbitals, i.e., doping with electron-deficient B [16]. Specifically, the vacant $2 p_{z}$ orbital of $\mathrm{B}$ conjugates with the carbon $\pi$ system to extract electrons. These electrons become active because of the low electronegativity of $\mathrm{B}$ and therefore can be used in the ORR. Moreover, the ORR performance can be optimized by taking advantage of the wide range of carbon nanostructures, e.g., the reduction current density can be increased by increasing the specific surface areas (SSAs) of carbon nanomaterials [17]. Compared with commercial $\mathrm{Pt} / \mathrm{C}$ catalysts, carbon-based metal-free ORR electrocatalysts show high catalytic activities and have the merits of longevity, abundance of raw materials, and $\mathrm{CO}$ and methanol tolerance. There have recently been a few review papers on the synthesis and performance of carbon-based nanomaterials for the ORR $[14,15]$. In this paper, we give a brief review of the main areas of progress in this emerging field, in combination with updates based on studies by our group. Special attention is paid to N and B mono- or co-doped carbon nanostructures, and the correlation between the ORR activity and the electronic structure of $s p^{2}$ carbon materials.

\section{Carbon-based metal-free ORR electrocatalysts}

\subsection{N-doped carbon nanomaterials}

Carbon-based metal-free ORR electrocatalysts are usually obtained by doping $s p^{2}$ carbon materials with different dopants.

The study of $\mathrm{N}$-doped metal-free ORR electrocatalysts originates from studies of the active sites of TM-N-C (TM = Fe, Co)
ORR catalysts. The general consensus is that TM-N moieties embedded in the carbon matrix are the ORR active sites, but some researchers have suggested that the metal-free $\mathrm{N}-\mathrm{C}$ moiety itself could catalyze the ORR [18]. In 2005, Stevenson et al. [19] observed that N-doped carbon nanofibers showed weak ORR activity in aqueous $\mathrm{KNO}_{3}$ solutions at neutral to basic $\mathrm{pH}$ through a two-electron process. In 2006, Ozkan et al. [20] found that $\mathrm{N}$-containing carbon deposited on pure alumina with less than $1 \mathrm{ppm}$ metal contamination was also ORR active in an acidic electrolyte, indicating that TM species are unnecessary. The explosion of interest in this topic started in 2009, when Dai's group [13] reported excellent ORR performance by $\mathrm{N}$-doped carbon nanotube (NCNT) arrays in alkaline media, comparable to those of commercial $\mathrm{Pt} / \mathrm{C}$ in terms of onset potential, reduction current density, and electron transfer number. In addition, the catalyst had the advantages of inertness to $\mathrm{CO}$ and methanol. Since then, a wide range of $\mathrm{N}$-doped carbon nanostructures have been synthesized, e.g., N-doped graphene [21], carbon nanocups [22], $\mathrm{C}_{3} \mathrm{~N}_{4}$ [23], and mesoporous carbon [24], with different morphologies and structural characteristics. Issues of common interest regarding this topic include investigation of the origin of the ORR activity and further improvements in ORR performance, e.g., by increasing the SSA. Here, we take $\mathrm{N}$-doped carbon nanocages (NCNCs) as an example for detailed examination [17].

NCNCs were prepared using an in situ MgO template method with pyridine as the precursor. The typical morphology of NCNCs is different from those of CNTs and NCNTs synthesized from benzene and pyridine precursors, respectively, by chemical vapor deposition (CVD) [25,26], as shown in Fig. 2a-c. The three-dimensional cuboidal morphology of NCNCs avoids the drawback of irreversible agglomeration and restacking caused by strong $\pi-\pi$ interactions that arise with graphene [27]. The 

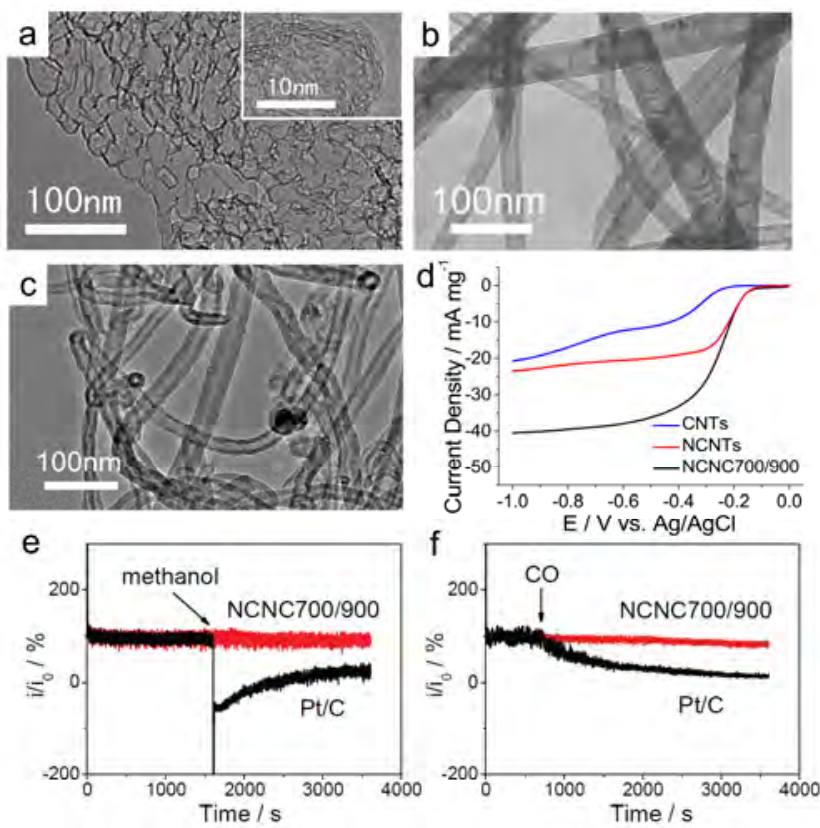

Fig. 2. Transmission electron microscopy (TEM) images and electrocatalytic characterization of three carbon-based nanomaterials [17,26]. (a-c) TEM images of NCNCs, NCNTs, and CNTs. Inset in (a) is a high-resolution TEM. (d) Rotating disk electrode (RDE) voltammograms. Rotation rate: $2500 \mathrm{r} / \mathrm{min}$, scan rate: $10 \mathrm{mV} / \mathrm{s}$. (e, f) Chronoamperometric responses of NCNCs at bias voltage of $-0.4 \mathrm{~V}$. The arrow indicates the addition of $2 \%(\mathrm{v} / \mathrm{v})$ methanol (e) and $10 \%(\mathrm{v} / \mathrm{v}) \mathrm{CO}(\mathrm{f})$ to the electrochemical cell; $i_{0}$ is the initial current. All the measurements were performed in $\mathrm{O}_{2}$-saturated $\mathrm{KOH}$ solution $(0.1 \mathrm{~mol} / \mathrm{L})$. Curves for $\mathrm{Pt} / \mathrm{C}$ are shown for comparison.

obtained NCNCs have high N-doping and large SSAs without any TM residues, so they are good example for demonstrating $\mathrm{N}$-doping and morphology effects on the ORR performance. A series of NCNCs grown at temperatures ranging from 600 to $900{ }^{\circ} \mathrm{C}$ were systematically characterized. It was found that the NCNCs grown at $700{ }^{\circ} \mathrm{C}$ and post-annealed at $900{ }^{\circ} \mathrm{C}$ (denoted by NCNC700/900) simultaneously possess a large SSA (884 $\mathrm{m}^{2} / \mathrm{g}$ ) and good graphitization. Electrochemical tests demonstrate that, in an alkaline electrolyte, the onset potential of NCNC700/900 is almost the same as that of NCNTs, but the current density is much higher. This is mainly attributed to the surface area of NCNC700/900 (884 m²/g) being much larger than that of NCNTs (ca. $200 \mathrm{~m}^{2} / \mathrm{g}$ ). The ORR performance is comparable to those of commercial Pt/C electrocatalysts, with superior stability towards methanol crossover and $\mathrm{CO}$ poisoning (Fig. 2e and f). There is no interference by ORR-active metal impurities in NCNCs, so the experimental results confirm that the ORR activity originates from $\mathrm{N}$-doped carbon species [17]. The excellent ORR performance, convenient preparation, large surface area, and high $\mathrm{N}$ content of NCNCs suggest that they have great potential for use in fuel cells.

\subsection{B-doped carbon nanomaterials}

As mentioned in the introduction, vacant orbitals that can conjugate with delocalized $\pi$ orbitals may also activate carbon $\pi$ electrons for ORR use. The element most likely to achieve this effect is B, which has an atomic radius close to that of carbon, but one less electron. Research on B-doped carbon nanomaterials for the ORR is rare compared with that on the $\mathrm{N}$-doped counterparts, because the idea that electron-deficient B-doped $s p^{2}$ carbons can catalyze the ORR, which require electrons, is counterintuitive. However, doping of $s p^{2}$ carbon materials is more difficult with $\mathrm{B}$ than with $\mathrm{N}$. For example, the highest reported B-doping level (2.13\%) [16] is far less than that in the case of N (12\%) [24], and B-doping is often accompanied by a high $\mathrm{O}$ content because of the strong affinity between 0 and B. We take B-doped CNTs (BCNTs) as an example to show how B doping overcomes the inertness of CNTs and turns them into ORR electrocatalysts [16].

BCNTs were prepared by CVD with benzene, triphenylborane, and ferrocene as the precursors and catalyst. The shapes of the BCNTs evolve from straight to bamboo-like, and eventually to twisted nanotubes, with increasing amounts of $B$ dopant in the range $0-2.13 \%$. This is associated with the B-C bond being about $0.5 \%$ longer than the $\mathrm{C}-\mathrm{C}$ bond [28]. X-ray photoelectron spectroscopy results show a rich collection of $\mathrm{B}$ chemical states in $\mathrm{BCNTs}$, including $\mathrm{BC}_{3}, \mathrm{BCO}_{2}$, and $\mathrm{BC}_{2} \mathrm{O}$ moieties. Electrochemical tests demonstrate that the ORR catalytic performance in alkaline solution progressively improves with increasing B content, as reflected in the increased reduction current and the positively shifted onset and peak potentials (Fig. 3a). Just like their N-doped counterpart, BCNTs are not affected by methanol crossover and CO poisoning (Fig. 3c, d). Theoretical calculations indicate that the electrocatalytic activ-

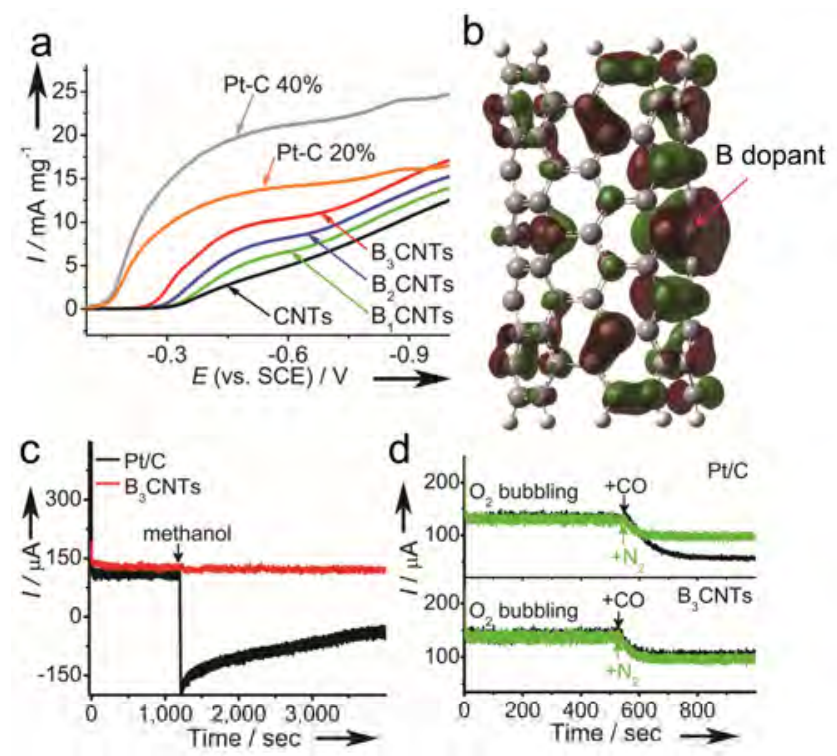

Fig. 3. ORR activities and important molecular orbitals of BCNTs [16]. (a) RDE voltammograms of catalysts for ORR in $\mathrm{O}_{2}$-saturated $\mathrm{NaOH}$ electrolyte $(1 \mathrm{~mol} / \mathrm{L})$ at a scan rate of $50 \mathrm{mV} / \mathrm{s}$ and a rotation speed of $2500 \mathrm{r} / \mathrm{min}$. (b) HOMO-1 of BCNT(5,5). (c) Methanol crossover tests performed by introducing $1.5 \mathrm{~mL}$ of methanol into the electrolyte at $1200 \mathrm{~s}$. (d) CO poisoning tests performed by introducing additional CO, at the same flow rate as $\mathrm{O}_{2}$, into the electrolyte at $520 \mathrm{~s}$. B $\mathrm{B}_{x} \mathrm{CNTs}(x=1$, 2,3 ) denotes BCNTs with increased B contents. For comparison, corresponding examinations of CNTs and commercial Pt/C catalysts $(20$ and $40 \mathrm{wt} \%$ Pt loading) were also carried out. 
ity of BCNTs for the ORR stems from conjugation between the vacant $2 p_{z}$ orbital of $\mathrm{B}$ and the $\pi$ orbital of carbon. The accumulated electrons in the $2 p_{z}$ orbital are active as a result of the small electronegativity of $\mathrm{B}$, and therefore become the HOMO electrons in BCNTs, and can be used in the ORR (Fig. 3b).

\subsection{B-N co-doped nanomaterials}

Because both $\mathrm{B}$ and $\mathrm{N}$ mono-doping can induce ORR activity of $s p^{2}$ carbons, intuitively, co-doping with $\mathrm{B}$ and $\mathrm{N}$ is a possible route for optimizing the activities of carbon-based metal-free ORR electrocatalysts. In 2007, Ozaki et al. [29] tried co-doping by carbonization of poly(furfuryl alcohol) containing both a $\mathrm{BF}_{3}-\mathrm{CH}_{3} \mathrm{OH}$ complex and melamine. The obtained B-N codoped carbons give higher reduction currents than their $\mathrm{B}$ and $\mathrm{N}$ mono-doped counterparts in acidic media. Recently, Dai's group reported that B-N co-doped CNTs [30] and graphene [31] are excellent ORR electrocatalysts in alkaline solution. Despite these promising results, the irregular variations in ORR activities with respect to the $\mathrm{B} / \mathrm{N}$ ratios and contents are problematic and the cause is complex. For example, the ORR performance of a certain $\mathrm{B}-\mathrm{N}$ co-doped graphene is even better than those of commercial Pt/C catalysts, but the performance of some others is much worse, despite the higher $\mathrm{B}$ and $\mathrm{N}$ contents [31]. There is a fundamental issue with $\mathrm{B}-\mathrm{N}$ co-doped carbon materials, i.e., whether the $\mathrm{B}$ and $\mathrm{N}$ dopants are bonded together or located separately. Because of the compensation effect between $\mathrm{p}$ - and n-type dopants, these two cases correspond to totally different electronic structures, with different conjugation effects in the delocalized $\pi$ system, which eventually leads to distinct ORR activities. This issue has been systematically studied by our group [32]. To obtain co-doped CNTs dominated by separated $\mathrm{B}$ and $\mathrm{N}$, sequential doping was used, i.e., BCNTs were prepared first and then doped with $\mathrm{N}$ by $\mathrm{NH}_{3}$ post-treatment. The bonded B-N co-doped CNTs were prepared by a simultaneous co-doping route, i.e., the $\mathrm{B}$ and $\mathrm{N}$ sources were mixed together in the precursor during CVD growth. Electrochemical tests show that the bonded material cannot, but the separated one can, convert inert CNTs into ORR electrocatalysts in alkaline solution (Fig. 4). Theoretical studies indicate that the bonded and separated cases correspond to unactivated and activated $\pi$ electrons, respectively, which provides sound evidence for correlation of the ORR activities of carbon materials with $\pi$ electron activation. At almost the same

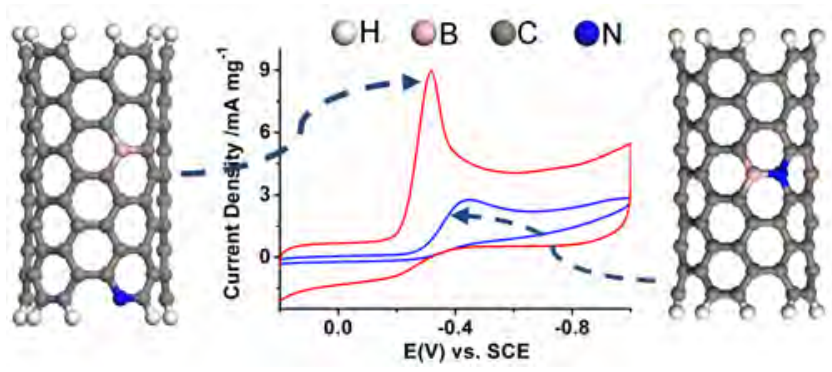

Fig. 4. Schematic diagrams of two types of B-N co-doped CNTs and their ORR activities [32]. (a) Separated B-N co-doped CNTs with high ORR activity; (b) Bonded B-N co-doped CNTs with low ORR activity. time, Qiao's group [33] reached the same conclusion regarding B-N co-doped graphene. They incorporated N and B sequentially into the graphene domain and observed an enhanced synergistic coupling effect that can facilitate the electrocatalytic ORR.

\subsection{Other carbon-based ORR catalysts}

Besides B and N, other non-metallic elements such as S, I, and $\mathrm{P}$ have also been doped into carbon materials to enhance the ORR catalytic activity [34-37]. It is interesting that S-doped graphene demonstrates a good onset potential and reduction current density, comparable to those of commercial Pt/C catalysts [37]. As a result of the large atomic radius of $S$ and the long S-C bond, $\mathrm{S}$ is not likely to participate directly in $\pi$ conjugated systems but creates defects and distortions that perturb the delocalized $\pi$ electrons. Mechanistic studies of non-metal-doped carbon materials are quite rare, and further in-depth investigations are needed.

\section{Summary and perspective}

Carbon-based metal-free ORR electrocatalysts are currently being intensively researched, and various carbon-based nanostructures with excellent ORR performance are being developed. From the different ORR performance of mono- and co-doped carbons to date, we can conclude that the ORR activity correlates with activation of $\pi$ electrons in $s p^{2}$ carbon materials. The extra electrons from $\mathrm{N}$, the vacant orbital from $\mathrm{B}$, and the defects created by $\mathrm{S}$ and $\mathrm{P}$ can all activate carbon $\pi$ electrons to different degrees, so it is easier for $\mathrm{O}_{2}$ molecules to extract electrons, enabling the ORR to proceed. Based on this understanding, together with the status of current research on cathodes in commercial fuel cells, the following are proposed.

(1) Multi-doping is a promising way of achieving high-performance ORR activity for $s p^{2}$ carbon materials. More attention should be devoted to regulating the configuration of the dopants. Doping with different dopants can cause various synergetic effects; some are postive for the ORR, but others are not.

(2) The ORR proceeds on the surface active sites of electrocatalysts, thus the SSA plays an important role, especially in the reduction current density. A high SSA is usually accompanied by a large amount of topological defects, which may also contribute to ORR activity, e.g., giving a better onset potential. However, a large SSA may cause low electron conductivity, which is a serious drawback for the ORR. A good balance between SSA and electron conductivity is therefore essential in optimizing high-performance carbon-based ORR electrocatalysts.

(3) Carbon-based metal-free electrocatalysts have the merits of excellent activity, longevity, abundance of raw materials, and great $\mathrm{CO}$ and methanol tolerance, which is highly desirable for fuel cells. However, to date, excellent performance has mostly been obtained in alkaline media. In acidic media, which are used in most commercial proton exchange membrane fuel cells, these catalysts only show low activities, far below the practical requirements. The development of carbon-based 


\section{Graphical Abstract}

Chin. J. Catal., 2013, 34: 1986-1991 doi: 10.1016/S1872-2067(12)60713-X

\section{A mini review on carbon-based metal-free electrocatalysts for oxygen reduction reaction}

Lijun Yang, Yu Zhao, Shen Chen, Qiang Wu, Xizhang Wang, Zheng Hu* Nanjing University

Advanced metal-free carbon-based oxygen reduction reaction (ORR) electrocatalysts are reviewed in combination with updates from studies in our laboratory, and the correlation between ORR activity and the electronic structure of $s p^{2}$ carbon materials is highlighted.

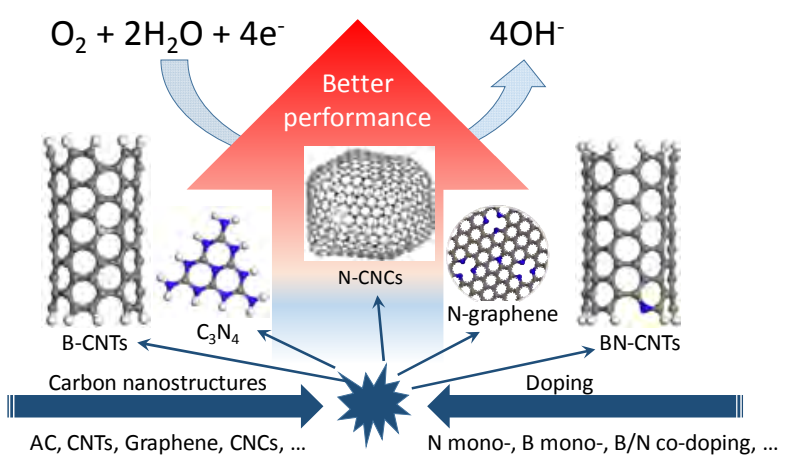

Y W, Hu Z. Angew Chem Int Ed, 2011, 50: 7132

[17] Chen S, Bi J Y, Zhao Y, Yang L J, Zhang C, Ma Y W, Wu Q, Wang X Z, Hu Z. Adv Mater, 2012, 24: 5593

[18] Garsuch A, Bonakdarpour A, Liu G, Yang R, Dahn J R. Handbook of Fuel Cells: Advances in Electrocatalysis, Materials, Diagnostics and Durability. Vol. 5. In: Vielstich W, Gasteiger H A, Yokokawa H, Eds. New York: John Wiley and Sons, 2010. 73

[19] Maldonado S, Stevenson K J.J Phys Chem B, 2005, 109: 4707

[20] Matter P H, Ozkan U S. Catal Lett, 2006, 109: 115

[21] Qu L T, Liu Y, Baek J B, Dai L M. ACS Nano, 2010, 4: 1321

[22] Tang Y F, Allen B L, Kauffman D R, Star A. J Am Chem Soc, 2009, 131: 13200

[23] Zheng Y, Jiao Y, Chen J, Liu J, Liang J, Du A J, Zhang W M, Zhu Z H, Smith S C, Jaroniec M, Lu G Q, Qiao S Z. J Am Chem Soc, 2011, 133: 20116

[24] Yang W, Fellinger T-P, Antonietti M. J Am Chem Soc, 2011, 133: 206

[25] Tian Y J, Hu Z, Yang Y, Wang X Z, Chen X, Xu H, Wu Q, Ji W J, Chen Y. J Am Chem Soc, 2004, 126: 1180

[26] Chen H, Yang Y, Hu Z, Huo K F, Ma Y W, Chen Y, Wang X S, Lu Y N.J Phys Chem B, 2006, 110: 16422

[27] Li D, Kaner R B, Science, 2008, 320: 1170

[28] Panchakarla L S, Subrahmanyam K S, Saha S K, Govindaraj A, Krishnamurthy H R, Waghmare U V, Rao C N R. Adv Mater, 2009, 21: 4726

[29] Ozaki J-i, Kimura N, Anahara T, Oya A. Carbon, 2007, 45: 1847

[30] Wang S Y, Iyyamperumal E, Roy A, Xue Y H, Yu D S, Dai L M. Angew Chem Int Ed, 2011, 50: 11756

[31] Wang S Y, Zhang L P, Xia Z H, Roy A, Chang D W, Baek J -B, Dai L M. Angew Chem Int Ed, 2012, 51: 4209

[32] Zhao Y, Yang L J, Chen S, Wang X Z, Ma Y W, Wu Q, Jiang Y F, Qian W J, Hu Z.J Am Chem Soc, 2013, 135: 1201

[33] Zheng Y, Jiao Y, Ge L, Jaroniec M, Qiao S Z. Angew Chem Int Ed, 2013, 52: 3110

[34] Liu Z W, Peng F, Wang H J, Yu H, Zheng W X, Yang J. Angew Chem Int $E d, 2011,50: 3257$

[35] Yang D S, Bhattacharjya D, Inamdar S, Park J, Yu J S. J Am Chem Soc, 2012, 134: 16127

[36] Yao Z, Nie H, Yang Z, Zhou X M, Liu Z, Huang S M. Chem Commum, 2012, 48: 1027

[37] Yang Z, Yao Z, Li G F, Fang G Y, Nie H G, Liu Z, Zhou X M, Chen X A, Huang S M. ACS Nano, 2012, 6: 205 


\title{
碳基无金属氧还原电催化剂研究的新进展
}

\author{
杨立军 ${ }^{\dagger}$, 赵 宇 ${ }^{\dagger}$, 陈 盛, 吴强, 王喜章, 胡 征
}

南京大学化学化工学院, 介观化学教育部重点实验室, 江苏南京 210093

摘要: 以替代铂为目标的高性能廉价氧还原电催化剂的研究为当今科学前沿. 近年来人们发现, 掺杂的碳基纳米结构具有催化活 性高、稳定性好、资源丰富、抗 $\mathrm{CO}$ 和抗甲醇能力强等优点, 是一种新型无金属氧还原电催化剂, 具有替代铂基催化剂的潜力. 本 文结合作者课题组的最新研究成果, 简要综述了碳基无金属氧还原电催化剂研究的主要进展, 重点关注了富电子氮和缺电子硼单 /共掺杂的碳纳米结构的氧还原催化性能及其与电子结构的关系, 展望了碳基无金属氧还原催化剂的发展策略与前景.

关键词: 氧还原反应; 无金属电催化剂; 碳基纳米结构; 掺杂

收稿日期: 2013-08-18. 接受日期: 2013-09-11. 出版日期: 2013-11-20.

†共同第一作者.

*通讯联系人. 电话: (025)83686015; 传真: (025)83686015; 电子信箱: zhenghu@nju.edu.cn

基金来源：国家自然科学基金(51232003, 21203092, 21173114).

本文的英文电子版由Elsevier出版社在ScienceDirect上出版(http://www.sciencedirect.com/science/journal/18722067). 